\title{
IMPLICAÇÕES DO VELHO E DO NOVO PARADIGMA EM CIÊNCIA PARAA EDUCAÇÃO
}

\section{CHADDAD, Flávio Roberto}

Graduado em Engenharia Agronômica pela Unesp/Botucatu e em Ciências Biológicas pela Unip/Bauru; especialista em Educação Ambiental pela Unesp/Botucatu e mestre em Educação pela PUC-Campinas.

E-mail: flaviorobertochaddad@hotmail.com.

\begin{abstract}
RESUMO
Grande parte dos problemas da escola pública deriva de uma visão de ensino fragmentada, de metodologias obsoletas, de um currículo inflexível, de um professor transmissor de uma Ciência inquestionável e de um aluno depositário desse conteúdo. Todos esses aspectos são produtos da visão de mundo oriunda da Ciência clássica. Como contraponto a esse paradigma em educação, oriundo da Ciência clássica, se está construindo um outro. Este tem as suas bases fundamentadas, principalmente, na Teoria da Relatividade, na Teoria Quântica e Teoria das Estruturas Dissipativas e implica um processo educativo vivo, em que o aluno não se limita a ser apenas um receptor de conteúdos, mas constrói conhecimentos com seus pares e com o seu professor, que passa a ser facilitador de um conhecimento transitório. O objetivo deste estudo é analisar, através de uma revisão bibliográfica, as implicações do velho e do novo paradigma científico para a educação.
\end{abstract}

Palavras-chave: Velho Paradigma Científico; Novo Paradigma Científico; Educação.

\begin{abstract}
Most problems of public school come from a fragmented teaching vision, obsolete methodologies, an inflexible curriculum, teachers as transmitters of an unquestionable science and students who are depositary of this content. All these aspects are products of the worldview originated from classical science. As a counterpoint to this paradigm in education, derived from the classical science, another is being built, whose foundation is based mainly on the Theory of Relativity, on the Quantum Theory and on the Dissipative Structures Theory. It involves a live educational process, in which the student is not limited to be only a content receiver, but to construct knowledge with peers and their teacher, who becomes the facilitator of a transitory knowledge. The aim of this study is to analyze, by means of a literature review, the implications of the old and the new scientific paradigms for education.
\end{abstract}

KeYwORDs: Old scientific paradigm; New scientific paradigm; Education. 


\section{INTRODUÇÃO}

Hoje estamos assistindo à falência da escola pública. As escolas estão sem nenhuma condição de infraestrutura, com falta de manutenção, com condições sanitárias inadequadas de funcionamento e com falta de material didático. As crianças e adolescentes se aglutinam nas salas de aula, na maioria das vezes, sem saber ler e escrever, só ajudam a piorar o caos escolar gerando, cada vez mais e mais, indisciplina. Além disso, verificase que a aprendizagem do aluno não é o foco. De um modo geral, as escolas não estão preparadas para garantir o processo de ensino pelo professor e a aprendizagem do aluno, desprendem mais energia com as rotinas administrativas e deixam de lado a gestão pedagógica. Outro ponto fundamental se relaciona com a existência de profissionais desmotivados e sem qualificação necessária, fruto de uma política de baixa valorização do professor, o que, nos últimos anos, vem gerando uma baixa atratividade dos cursos de licenciaturas. Ainexistência de um plano de carreira com salários dignos afeta todo o sistema, exige do professor um malabarismo descomunal para garantir sua sobrevivência pessoal e familiar. Enfim, a escola virou um depósito de alunos, onde os alunos fingem que aprendeme os professores, devido a todo esse processo, ensina. A progressão continuada veio selar a pedra fundamental numa situação que vem sendo mantida há anos, por vários governos (MORAES, 2002).

Pode-se dizer que tudo isso é fruto de uma visão fragmentada, desarticulada, descontínua e compartimentada da educação. Esses fatos colaboram para o prevalecimento das atuais taxas de analfabetismo, evasão, repetência, baixa qualidade do ensino e tantas outras mazelas da educação brasileira. A escola não cumpre seu papel, está completamente dissociada do mundo. A sociedade em geral está insatisfeita com a qualidade do ensino oferecido, mas muitas mães de alunos também não acompanham seus filhos durante o processo de ensino e aprendizagem, as suas deficiências, na verdade esquecem que têm filhos. Este é um depoimento de um professor que já passou anos no ensino básico. As reuniões que são realizadas nas escolas, tencionando chamar a comunidade, os pais, para dentro dos muros escolares, na verdade não os atraem. Disso resulta um aluno que não sai qualificado do banco escolar; sai, muitas vezes, sem saber ler, escrever e sem saber fazer cálculos numéricos, e ninguém o cobra por isso. $\mathrm{O}$ importante é perceber que esses problemas existem e permanecem há várias décadas, são completamente interdependentes uns dos outros e suas soluções requerem uma visão sistêmica de realidade, uma percepção da complexidade da realidade a ser transformada (MORAES, 2002).

Como exemplo dessa percepção fragmentada da educação, tem-se a política educacional do Estado de São Paulo, voltada à implantação de um currículo único e ao acompanhamento dos resultados, por meio do Sistema de Avaliação do Rendimento Escolar do Estado de São Paulo - SARESP. Essa política contou com os seguintes objetivos: adoção de um currículo único e fechado; utilização de material instrucional padronizado; acompanhamento dos resultados por supervisão cerrada através de avaliação; uso dos resultados da avaliação como critério para a concessão de vantagens salariais (bônus); utilização de incentivo monetário para aumento de produtividade do trabalho. Mais do que uma pretensa melhoria, a política revela o uso de uma racionalidade técnica instrumental autoritária que não encontra fundamento no processo democrático de formação humana, para a autonomia da escola na construção do seu projeto político-pedagógico e para o desenvolvimento pessoal e profissional dos professores (RUSSO; CARVALHO, 2010).

Como uma de muitas situações responsáveis pelo fracasso do ensino público, que muitas vezes passam imperceptíveis para a maioria dos profissionais da educação, está a implicação do velho paradigma científico para a educação.

Segundo Moraes (2002), na área educacional, o velho paradigma ainda dominante - sob as influências de Descartes e Newton -, continua gerando padrões de comportamentos preestabelecidos, com base em um sistema de referência que ensina a não questionar, a não expressar o pensamento divergente, a aceitar passivamente a autoridade, a ter certeza das coisas. 
Onde está a origem disso tudo? Observa-se que a escola atual continua influenciada pelo universo estável e mecanicista de Newton, pela filosofia reducionista cartesiana, pelo determinismo mensurável, pela visão fechada de um universo linearmente concebido, estático. Consequentemente, é uma escola submetida a um controle rígido, a um sistema paternalista autoritário e dogmático -, fruto da própria formação da sociedade ocidental, conforme a tese de Engels (1995), A origem da Propriedade Privada, da Família e do Estado, não percebendo as mudanças ao seu redor e, na maioria das vezes, resistindo a elas:

Uma escola que continua dividindo o conhecimento em assuntos, especialidades, subespecialidades, fragmentando o todo em partes, separando o corpo em cabeça, tronco e membros, as flores em pétalas, a história em fatos isolados, sem se preocupar com a integração, a interação, a continuidade e a síntese. É o professor o único responsável pela transmissão de conhecimento, continua vendo o aprendiz como uma tábula rasa, produzindo seres subservientes, obedientes, castrados em sua capacidade criativa, destituídos de outras formas de expressão e solidariedade (MORAES, 2002, p.51).

Além dessa educação, que foi designada por Freire apud Moraes (2002) como bancária, em que o conhecimento em partes e descontextualizado é depositado na "cabeça de cada aluno", há também o desinteresse por aquilo que está fora do alcance de nossos olhos, por aquilo que não nos afeta diretamente, como o sofrimento e a dor do outro. O individualismo presente e cultivado no espaço escolar também traz sérias implicações éticas sobre quais indivíduos formaremos e estamos formando nos dias de hoje.

Segundo Oliveira (2010), esse modo de pensar o mundo é fruto do velho paradigma mecanicista, pelo qual somos levados a negligenciar as tendências integrativas em favor das autoafirmativas, isoladas, competitivas. Essas tendências não são apenas incentivadas, mas também recompensadas e reforçadas.
É o que podemos notar se olharmos com mais atenção para a história da humanidade: o imperialismo, a degradação da natureza, a discriminação de povos menos desenvolvidos tecnologicamente, a opressão da mulher e a luta por poder econômico são alguns exemplos de como o mundo foi organizado a partir de uma lógica funcional, paternalista e dominadora, que nós reproduzimos diariamente nas salas de aula.

Hoje, porém, estamos vivenciando um processo em que um novo paradigma, baseado sobretudo na Física Quântica, na Teoria da Relatividade e na Teoria das Estruturas Dissipativas, se está constituindo, mas ainda falta sua plena enunciação na vida de todos e, principalmente, nos processos educacionais, que ainda obedecem à velha fórmula descrita acima, ou seja, ao paradigma científico dos séculos XVI e XVII.

$\mathrm{O}$ novo paradigma reconhece a interdependência existente entre os processos de pensamento e de construção do conhecimento e o ambiente em geral. Ele colabora para resgatar a visão de contexto, através da Física Quântica e da Teoria Sistêmica, e não separa os indivíduos do mundo em que vivem e de seus relacionamentos, os promovema seres interdependentes, reconhecendo que a nossa vida está entrelaçada com a natureza. De acordo com Guattari (2001), compreende o perfeito entrosamento dos indivíduos comos processos subjetivos, sociais e naturais.

O objetivo deste trabalho é analisar as implicações do velho e do novo paradigma em Ciência para a educação.

\section{O QUE É PARADIGMA?}

Paradigma pode ser entendido por um exemplo, um modelo, uma referência, uma diretriz, um parâmetro, um rumo, uma estrutura, ou até mesmo umideal. Algo digno de ser seguido. Podemos dizer que um paradigma é a percepção geral e comum - não necessariamente a melhor - de se ver determinada coisa, seja um objeto, seja um fenômeno, seja um conjunto de ideias. Ao mesmo tempo, ao ser aceito, um paradigma serve como critério de verdade e de validação e reconhecimento nos meios em que é adotado. Foi o físico Thomas Kuhn que o utilizou como um termo científico em seu livro $A$ 
Estrutura das Revoluções Científicas, publicado em 1962 (STIGAR, 2010).

Segundo Stigar (2010), para Kuhn a palavra paradigma pode ser entendida como uma concepção de mundo oriunda da área científica. Segundo ele, paradigma pretende sugerir que "certos exemplos da prática científica atual - tanto na teoria quanto na aplicação - estão ligados a modelos conceptuais de mundo dos quais surgem certas tradições de pesquisa". Em outras palavras, uma visão de realidade atrelada a uma estrutura teórica apriorística, aceita, estabelece uma forma de compreender e interpretar intelectualmente o mundo segundo os princípios constantes do paradigma em vigor.

Isso traz repercussões a toda a sociedade, conforme a definição e explicação dada de paradigma por Capra (1999). Segundo o autor, paradigma engloba o pensamento, a percepção e os valores que formam uma determinada visão de realidade. Este paradigma que está em transformação, ou em questão, dominou nossa cultura durante muitas centenas de anos, ao longo dos quais modelou nossa sociedade ocidental e influenciou significativamente o resto do mundo. Ele compreende um certo número de ideias e valores. Valores que estiveram associados a várias correntes da cultura ocidental, entre elas a Revolução Científica, o Iluminismo e a Revolução Industrial. Incluem a crença de que o método científico é a única abordagem válida do conhecimento; a concepção do universo como um sistema mecânico composto de unidades materiais elementares; a concepção da vida em sociedade como uma luta competitiva pela existência; do crescimento econômico e tecnológico. Nas descobertas científicas que se iniciaram a partir do começo do século passado verificou-se que todas essas ideias e valores estão seriamente limitados e necessitam de uma revisão radical, uma nova reconstrução.

O VELhO PARAdigma E SUAS IMPLICAÇões PARA A EDUCAÇÃo

Segundo Capra (1999; 2001; 2007), Moraes (2002) e Santos (2007), vivemos hoje sob a crise do paradigma moderno, nascido com a Ciência Moderna, que determinou o modo de ser e de agir do ser humano contemporâneo.

De maneira geral pode-se afirmar que o paradigma moderno, hoje em transição, começou a tomar vulto quando o italiano Galileu fez os primeiros experimentos que deram origem à racionalidade cientificista que temos atualmente, principalmente as pesquisas em astronomia. Imediatamente, na Filosofia, somou-se a Galileu o racionalismo dedutivo e reducionista de Descartes, o empirismo indutivista de Bacon e a fusão desses dois métodos por Newton. Antes desse modelo ou dessa nova visão de mundo, o paradigma dominante era o da Teologia, que vigorou durante a Idade Média e remetia a Deus a explicação de tudo e do todo. Porém, tido como imperfeito pelos avanços na Ciência, principalmente na Astronomia, foi, de uma vez por todas, deixado de lado pelo sistema analítico e dedutivo cartesiano, pelo método empírico ou indutivo de Bacon e pelas descobertas da gravitação universal da física newtoniana, que deram origem à mecânica clássica. No século XX, a partir da Mecânica Quântica, da Teoria da Relatividade e da Teoria das Estruturas Dissipativas, lançaram-se as bases de uma Nova Ciência, ou seja, de um novo paradigma em Ciência (CAPRA, 1999).

Mas quais são as ideias que permeiam o velho paradigma? Como o velho paradigma influenciou e influencia a educação? Quais foram as descobertas científicas nos campos da Biologia, Química e Física que se posicionaram como um divisor de águas e colocaram em xeque o velho paradigma em Ciência? Quais são os seus reflexos para a educação? Quais teorias de aprendizagem se adaptam a essa nova realidade científica?

$\mathrm{O}$ velho paradigma é uma junção das ideias e pensamentos de Bacon, Descartes e Newton. Antes deles, Nicolau Copérnico se opôs ao pensamento ou concepção geocêntrica de Ptolomeu e da Bíblia, ou seja, onde a Terra era o centro do Universo. Galileu Galilei marcou o nascimento do experimentalismo científico ao substituir a argumentação lógica da dialética formal pela observação dos fatos em si mesmos, reafirmando, por meio da metodologia científica, a visão 
do sistema solar lançada por Copérnico. Segundo Capra (1999), Galileu foi o primeiro a combinar a experimentação científica com o uso da linguagem matemática para formular as leis da natureza por ele descobertas; é, portanto, considerado o pai da Ciência moderna. A Filosofia está escrita nesse grande livro que permanece sempre aberto diante de nossos olhos; mas não se pode entendê-la se não aprendermos, primeiro, a linguagem e os caracteres em que ela foi escrita. Esta linguagemé a matemática, e os caracteres são triângulos, círculos e outras figuras geométricas.

Conforme Santos (2007):

As ideias que presidem a observação e a experimentação são as ideias claras e simples a partir das quais se pode ascender a um conhecimento mais profundo e rigoroso da natureza. Essas ideias são as ideias matemáticas. A matemática fornece à Ciência moderna não só o instrumento privilegiado de análise, como também a lógica da investigação, como ainda o modelo de representação da própria estrutura da matéria. Assim, para Galileu, o livro da natureza está escrito em caracteres geométricos, e Einstein não pensava diferente. Este pressuposto traz duas consequências básicas. Primeiro, conhecer significa quantificar. O que não é quantificável não é cientificamente relevante. Em segundo lugar, se assenta a redução da complexidade que é o mundo (SANTOS, 2007, p.14-15).

E essa redução vai estar presente, principalmente, nas regras do Discurso do Método de Descartes (2000). É uma das formas ou metodologia da obtenção ou revelação das leis que regem a natureza e que, conforme está implícita no universo em forma matemática desde Parmênides e Pitágoras, tem como ideia central de ordem e de estabilidade do mundo a ideia de que o passado se repete no futuro, não há criação, improviso ou novas situações que possibilitem uma reorganização por parte do aluno - ou seja, não há vida (RUSSELL, 2001).

Esta ideia mecanicista, reducionista e fragmentária de Ciência tomará corpo com o positivismo de Augusto Comte (1976) no século XIX, o qual influenciará decisivamente toda a Ciência moderna, inclusive as Ciências Sociais.

Segundo Capra (1999; 2001; 2007), Moraes (2002) e Santos (2007), nessa mesma época, Bacon descrevia seu método empírico de Ciência, conhecido como indutivo. Ele examinava casos particulares para chegar a explicações gerais. Outro filósofo cientista que acreditava e foi grande teorizador do experimentalismo foi David Hume. Ele defendia, junto com Locke, que nossas ideias são construídas com base em impressões sensíveis provenientes das experiências dos órgãos do sentido. Assim, o que conhecemos é aquilo que foi registrado em nossa mente pelos órgãos dos sentidos. Aquilo que não transformamos em impressões sensíveis não pode ser conhecido. As ideias inatas, aqui, não fazem sentido. René Descartes, por sua vez, acreditava no ideal de Arquimedes de uma hierarquia dedutiva de proposições. Para ele, o fundamento do empreendimento científico estava no raciocínio dedutivo. Dono do método analítico, propunha a decomposição dos problemas em suas partes e sua disposição em ordem lógica. Para Descartes (2000), quem conhece é o sujeito, o espírito humano, a razão.

Esses modelos ou formas de adquirir ou atingir conhecimento (Bacon, Descartes e Hume) são modelos subjetivistas que se centram no eu, em situação educacional, no indivíduo-aluno, que o privilegiam na aquisição do conhecimento, dispensando as relações, o contexto sociocultural-natural, o que agora vem sendo questionado pela Nova Ciência e pelas Teorias de Ensino e Aprendizagem. Por sua vez, a causalidade implícita nas leis gerais que regem o universo faz com que o conhecimento seja um conjunto de dados inquestionáveis, neutros, verdades científicas que são depositados linearmente, no espaço e tempo, na cabeça do educando (MORAES, 2002).

É de se perguntar, conforme Boaventura de Sousa Santos (2007): Onde se materializa a liberdade e a imprevisibilidade, a não linearidade, da ação humana em seu processo de conhecer? Para esses cientistas, 
o espírito humano obtém o conhecimento por meio de um ensino que Paulo Freire apud Moraes (2002) denominou ensino bancário, em que cada disciplina deposita na cabeça de cada aluno seus conteúdos em uma sequência lógica, determinada e linear, que cerceia a liberdade e o livre arbítrio, deixando de lado o sinergismo implícito nas relações, o aparecimento do novo a partir das contradições que estão imersas na realidade educacional, ou seja, a própria vida. É um ensino morto!

Entretanto, foi Isaac Newton quem complementou o pensamento de Descartes e de Galileu Galilei dando ao mundo uma visão maquínica, de acordo com a concepção cartesiana de natureza. Segundo Capra (1999), ele formulou as leis exatas do movimento para todos os corpos, sob a influência da lei da gravidade. A significação dessas leis reside em sua aplicação universal. Comprovou-se que eram válidas para todo o sistema solar, confirmando a visão mecanicista cartesiana de natureza. Conforme Moraes (2002), o universo newtoniano passou a ser um grande sistema mecânico que funcionava de acordo com leis físicas e matemáticas. Para ele, todos os fenômenos físicos estavam reduzidos ao movimento de partículas materiais causado pela atração mútua, pela força da gravidade. Essa força foi descrita por equações de movimento que constituem os fundamentos básicos da Mecânica clássica. A matéria seria composta de partículas homogêneas sólidas indestrutíveis, nas quais atua a força da gravidade. Era um mundo estático a flutuar num espaço vazio, que, para ser conhecido, necessitava ser decomposto em seus elementos. Assim, de acordo com Newton, Deus criou as partículas materiais, a força entre elas e as leis fundamentais do movimento. Tudo isso funciona como uma máquina governada por leis imutáveis, que controla a natureza e leva a Ciência a pressupor a existência do determinismo universal, ou seja, o universo funciona sempre da mesma maneira (CAPRA, 1999).

De acordo com Capra (1999), a concepção mecanicista de natureza que advém com esses cientistas, principalmente, Newton, está relacionada com um rigoroso determinismo, em que a gigantesca máquina cósmica é completamente causal e determinada. Tudo o que aconteceu teria tido uma causa definida e dado origem a um efeito definido, e o futuro de qualquer parte do sistema podia - em princípio - ser previsto com absoluta certeza, desde que seu estado, em qualquer momento dado, fosse conhecido em todos os seus detalhes.

Segundo Capra (1999), na esteira da física de Newton, Locke desenvolveu uma concepção atomística de sociedade, descrevendo-a em função de seu componente básico, o ser humano. Assim, como os físicos reduziram as propriedades dos gases aos movimentos de seus átomos, ou moléculas, também Locke tentou reduzir os padrões observados na sociedade ao comportamento de seus indivíduos:

Quando Locke aplicou sua teoria da natureza humana aos fenômenos sociais, foi guiado pela crença de que existem leis na natureza que governam a sociedade humana, leis semelhantes às que governam o universo físico. Tal como os átomos de um gás estabelecem um estado de equilíbrio, também os indivíduos humanos se estabilizariam numa sociedade num "estado de natureza". Assim, a função do governo não seria impor suas leis às pessoas, mas, antes, descobrir e fazer valer as leis naturais que existiam antes de qualquer governo ter sido formado. Segundo Locke, essas leis naturais incluiriam a liberdade e a igualdade entre todos os indivíduos, assim como o direito à propriedade, que representava os frutos do trabalho de cada um (CAPRA, 1999, p.64).

É necessário compreender a ideologia que está por trás dessas ideias. Ou seja, elas representam a base do que ficou conhecido como sistema liberal ou liberalismo econômico. Com esses ditames, a burguesia, baseada em Newton e em Locke, encontrou um amplo espaço para justificar os fatores necessários à sua realização e à criação de sua própria ideologia. O liberalismo, que foi um produto das classes médias em ascensão, em cujas mãos se desenvolviam o comércio e a indústria, opunha-se às arraigadas tradições de privilégios, tanto 
da aristocracia, quanto da monarquia. Afastando o poder da aristocracia e das monarquias sobre a política e a economia e calcado num indivíduo atomizado, que se realizaria no mercado, cujas bases eram supostas "leis naturais", implícitas na sociedade, que regeriam como uma mão invisível a economia e o bem-estar de todos, daí deriva-se a sua máxima: laissez faire, laissez passer. Essas ideias liberais, motivadas pelos filósofos iluministas, caíram como uma luva para a realização da burguesia mercantil (RUSSELL, 2001).

Esse legado liberal, na área educacional, existe e os educandos que não conseguem aprender são tidos como culpados por sua própria situação, muitas vezes "taxados" de deficientes - que nunca terão um futuro promissor ou conseguirão seguir uma carreira profissional. Enquanto as mazelas na educação continuam. É uma forma legitimada de opressão que, na maioria das vezes, acaba como abandono escolar. Assim, esse modelo de Ciência, essa nova racionalidade científica, passou a ser um modelo global, um modelo totalitário na medida em que negava a validade a todas as outras formas de conhecer que não seguissem esses métodos, que não rezavam pela mesma cartilha epistemológica e pelas suas regras metodológicas. Essa seria a sua característica principal e simbolizava a ruptura do novo paradigma com aqueles que o precederam; por isso, então, as tentativas das Ciências Humanas em adequar-se a esses postulados, em descobrir as leis da sociedade, não percebendo, assim, naquela época, o que se percebe hoje: que as Ciências Humanas têm as suas próprias especificidades.

E quais as influências mais sentidas na educação que são oriundas do velho paradigma em Ciência?

Segundo Moraes (2002, p.51), em termos de conteúdo, é um modelo que apresenta propostas voltadas para a aquisição de noções que enfatizam a assimilação, o conhecimento acumulado, o caráter abstrato e teórico do saber e a verbalização dele decorrente. De acordo com essa visão, conteúdo e produto são mais importantes que o processo de construção de conhecimento, já que o conteúdo é uma verdade inquestionável transmitida por um professor, muitas vezes autoritário, e dono do conteúdo e da verdade. Em termos metodológicos, as aulas são expositivas, os alunos fazem exercícios de fixação traduzidos em leituras e cópias, não há situaçõesproblema, que vão em direção à exploração da zona de desenvolvimento proximal do educando. Os horários e os currículos são rígidos, predeterminados, baseados na eficiência e na padronização, e calibrados pela mensuração que continua separando ganhadores de perdedores (os produtos). Em termos de avaliação, as provas são pontuais e assumem um papel central, determinando o comportamento do aluno, privilegiando a memória e a capacidade de expressar o que foi acumulado. A preocupação do professor é que o aluno adquira conhecimentos específicos, de maneira determinada.

Enfim, essa concepção de perceber a educação traduzem a visão empirista em que o conhecimento ocorre por força dos sentidos. É algo que vem do mundo do objeto (meio físico e social) e este é o determinante do sujeito, não o contrário. Esses princípios dizem respeito à corrente ou psicologia behaviorista (MORAES, 2002).

Assim, essas descobertas científicas, que durante séculos foram tidas como "verdades inquestionáveis", constituem o que podemos chamar de o velho paradigma em Ciências e trazem, como se viu, várias repercussões para a educação até os dias de hoje.

\section{O NOVO PARAdIGMA E SUAS IMPLICAÇÕES PARA A EDUCAÇÃO \\ Com relação ao novo paradigma em Ciência, quais} foram as ideias e descobertas científicas na Física, Química e Biologia que influenciaram e estão influenciando toda a visão de mundo operante, oriundo da visão mecanicista de universo e sociedade? Que contribuições elas trazem para a educação? Quais as teorias educacionais que melhor se aplicam a essa nova realidade?

Segundo Capra (1999), no início do século XIX surgiu a ideia de evolução - de mudança, crescimento e desenvolvimento. Ela surgiu da Geologia, em que estudos meticulosos de fósseis levaram os cientistas à conclusão de que o estado atual da Terra era o 
resultado de um desenvolvimento contínuo. Essas ideias constituíram o background intelectual para a formação mais precisa e de mais longo alcance do pensamento evolucionista: a teoria da evolução das espécies, em Biologia:

A descoberta da evolução em Biologia forçou os cientistas a abandonarem a concepção cartesiana segundo a qual o mundo era uma máquina inteiramente construída pelas mãos do Criador. O universo, pelo contrário, devia ser descrito como um sistema em evolução e em permanente mudança, na qual estruturas complexas se desenvolviam a partir de formas mais simples. Enquanto essa nova forma de pensamento era elaborada nas Ciências Humanas, conceitos evolucionistas surgiam também na Física. Contudo, enquanto a evolução, em Biologia, significou um movimento no sentido de uma ordem e uma complexidade crescentes, na Física passou a significar justamente o oposto - um movimento no sentido de uma crescente desordem (CAPRA, 1999, p.67).

Outra descoberta que abalou os alicerces da mecânica clássica foi a Teoria da Relatividade.

Conforme Santos (2007), Einstein revolucionou nossas concepções de espaço e tempo absolutos. Provou que:

Não havendo simultaneidade universal, o tempo e o espaço absolutos de Newton deixam de existir. Dois acontecimentos simultâneos num sistema de referência não são simultâneos noutro sistema de referência. As leis da Física e da Geometria assentam-se em medições locais. Os instrumentos de medida, sejam relógios ou metros, não têm magnitudes independentes, ajustam-se ao campo métrico do espaço, à estrutura que se manifesta mais claramente nos raios de luz (SANTOS, 2007, p.25).

De acordo com Moraes (2002), não há espaço nem tempo absolutos, mas sim medidas de distância e tempo que dependem do movimento do observador. E pelo fato de dependerem de um sistema de coordenadas são, portanto, relativas.

Segundo Capra (2001), considerava-se que esse espaço continha uma configuração definida de matéria a cada instante; agora, contudo, que a simultaneidade é vista como um conceito relativo, dependendo do estado de movimento do observador, não é mais possível definir esse instante preciso para a totalidade do Universo. Umevento distante que ocorre em algum instante particular para um observador pode ocorrer antes ou depois para um segundo observador. A teoria da relatividade demonstrou que todas as medidas que envolvem espaço e tempo perdem seu significado absoluto, e leva-nos a abandonar os conceitos clássicos de espaço e tempo absolutos. Aimportância fundamental desse desenvolvimento foi expressa com clareza por Sachs apud Capra (2001):

A verdadeira revolução que surgiu com a teoria de Einstein [...] foi o abandono da ideia de que o sistema de coordenadas do espaço-tempo possui significado objetivo como entidade física isolada. Em vez dessa ideia a teoria da relatividade implica o fato de que as coordenadas de espaço tempo são apenas os elementos de uma linguagem utilizada por um observador para descrever seu meio ambiente (CAPRA, 2001, p.132).

Outra teoria descoberta no início do século passado está relacionada com os átomos. A partir do experimento de Rutherford, que bombardeou átomos com partículas alfa, ficou demonstrado que os átomos, em vez de sólidos e indestrutíveis, possuem um espaço no qual se movem partículas extremamente pequenas - os elétrons.

Conforme Capra (1999), foi então que a Teoria Quântica deixou claro que os átomos consistem de vastas regiões no espaço onde partículas extremamente pequenas - os elétrons - se movimentam ao redor do núcleo; assim, em nenhum momento se pareciam com os objetos sólidos da física clássica. Essas unidades 
subatômicas da matéria são entidades muito abstratas e tem um aspecto dual. Dependendo de como as observamos, apresentam-se como partículas ou ondas; essa natureza dual também é apresentada pela luz, que pode adotar a forma de partículas ou ondas eletromagnéticas.

Segundo Moraes (2002), essa visão de dualidade no mundo subatômico colocou emquestão o conceito de realidade da matéria que é o próprio fundamento da visão mecanicista, ao descrever que, no nível subatômico, não se pode dizer que a matéria exista com clareza em lugares definidos. O correto seria dizer que ela apresenta uma tendência a existir e os eventos apresentam uma certa tendência a ocorrer, tendência essa que é expressa em termos de probabilidades, como as vibrações das cordas de um violão.

Heisenberg apud Santos (2007) foi o próximo a contribuir para colocar em xeque o mecanicismo clássico. Segundo ele, é impossível descrever, ao mesmo tempo, a exata posição e o momento de uma partícula. Esse princípio expressa que não se pode reduzir, simultaneamente, os erros da medição da velocidade e da posição das partículas; o que for feito para reduzir o erro de uma das medições aumenta o erro da outra.

Conforme Moraes (2002):

Essa afirmação introduz a ideia de que não conhecemos do real senão o que nele introduzimos, ou seja, senão nossa intervenção nele, caracterizando, portanto, uma intervenção do sujeito no objeto observado. Para Richard Olson o princípio da incerteza é tão importante quanto a Teoria da Relatividade, pois traz luz e esperança àqueles que acreditavam em um universo materialista e determinado como sendo algo insuportável e sem valor. Este princípio desafia a importante noção de causa e efeito que se constitui num dos pilares da Ciência clássica e do pensamento teológico e social tradicional, fragilizando, inclusive, o argumento determinista em todos os campos da Ciência, dando um novo suporte às especulações sobre o livrearbítrio (MORAES, 2002, p.62).
Outra condição teórica da crise do paradigma mecanicista é constituída pelos avanços do conhecimento nos domínios da Microfísica, da Química e da Biologia nos últimos 20 anos. Segundo Santos (2007):

A teoria das estruturas dissipativas e o princípio da ordem através das flutuações, de Ilya Prigogine, estabelecem que, em sistemas abertos, ou seja, em sistemas que funcionam nas margens da estabilidade, a evolução se explica por flutuações de energia que, em determinados momentos, nunca inteiramente previsíveis, desencadeiam espontaneamente reações que, por via de mecanismos não lineares, pressionam o sistema para além de um limite máximo de instabilidade e o conduzem a um novo estado macroscópico. Esta transformação irreversível e termodinâmica é o resultado da interação de processos microscópicos segundo uma lógica de auto-organização, numa situação de nãoequilíbrio. A situação de bifurcação, ou seja, o ponto crítico em que a mínima flutuação de energia pode conduzir a um novo estado, representa a potencialidade do sistema em ser atraído para um novo estado de menor entropia. Deste modo, a irreversibilidade nos sistemas abertos significa que estes são produtos da sua história (SANTOS, 2007, p.27-28).

De acordo com Moraes (2002, p.65), estruturas dissipadoras de energia são sistemas abertos, considerados complexos organizacionais sem equilíbrio, ou quase sem equilíbrio, e que caracterizam os sistemas vivos, diferentemente do universo estático e linear da física clássica. Esses sistemas funcionam nas margens da estabilidade, cuja evolução se explica por flutuações de energia que em determinados momentos desencadeiam, espontaneamente, reações. Estas, através de mecanismos não lineares, pressionam o sistema para além de um limite máximo de estabilidade, conduzindo-o a um novo estado macroscópico. A um salto. As instabilidades exigem 
Implicações do velho e do novo paradigma...

um fluxo de energia; elas dissipam energia. Há uma transformação irreversível e termodinâmica como resultado da interação de processos microscópicos, segundo uma lógica de auto-organização numa situação de não equilíbrio. De acordo com Prigogine apud Moraes (2002), esta ordem emerge pela entropia e não a despeito dela.

Segundo Santos (2007), a importância dessa teoria está na nova concepção da matéria e da natureza que propõe, uma concepção dificilmente de acordo com a que herdamos da física clássica. Em vez da eternidade, a história; em vez do determinismo, a imprevisibilidade; em vez do mecanicismo, a interpretação, a espontaneidade e a auto-organização; em vez da reversibilidade, a irreversibilidade e a evolução; em vez da ordem, a desordem; em vez da necessidade, a criatividade e o acidente. Assim, Moraes (2002) afirma:

O mundo passou então a ser visto ou concebido em termos de movimento, fluxo de energia e processo de mudança. Estas descobertas acabaram de esfacelar os principais conceitos da visão de mundo cartesiana e da mecânica newtoniana relacionados à noção de espaço e tempo absolutos, às partículas sólidas elementares, à objetividade científica, à causalidade e à separatividade, fazendo com que nenhum desses conceitos pudesse sobreviver às novas descobertas das Ciências (MORAES, 2002, p.59).

Dessa nova realidade científica surgem desdobramentos que estão mudando a maneira de como nós enxergamos o mundo e que, por sua vez, trazem implicações para toda sociedade e, consequentemente, para a educação. Segundo Moraes (2002, p.70-81), podemos enumerar esses princípios da seguinte forma:

1) Totalidade indivisa: Tanto a Teoria da Relatividade quanto a Teoria Quântica implicam a necessidade de olhar para o mundo como um todo indiviso, no qual todas as partes do universo, incluindo o observador e seus instrumentos, se fundem numa totalidade; um todo indivisivel em movimento fluente caracterizando o efetivo estado das coisas. A totalidade, segundo esta autora, é o ponto vital de qualquer paradigma que surge dessas ideias;

2) O pensamento sistêmico: Da noção de totalidade indivisível, do reconhecimento da interconexão existente entre os objetos e os fenômenos da natureza, resulta um dos critérios importantes do novo paradigma que se refere à "mudança do enfoque das partes para o todo". Segundo Capra (2007), no velho paradigma acreditava-se que a dinâmica do todo poderia ser entendida com base nas propriedades das partes, $e$ o mundo físico era visto como um conjunto de entidades separadas. No novo paradigma, a relação entre as partes e o todo é invertida. Isso implica que as propriedades das partes somente podem ser entendidas com base na dinâmica do todo;

3) Um mundo em holomovimento: Essa totalidade indivisa se encontra em holomovimento, um movimento contínuo, indefinível e imensurável. Para Bohm apud Moraes (2002), holomovimento é a esfera do que é manifesto e que está num movimento flutuante e abstrato. Seu movimento básico é o recolhimento e o desdobramento e, para ele, toda a existência é expressão básica do holomovimento que se manifesta numa forma relativamente estável. Todos os sistemas são organismos vivos, naturais, abertos, revelações desdobradas de totalidades que implicam interações e interdependência de suas partes $e$ estruturas específicas, possuindo uma natureza intrinsecamente dinâmica, não apresentando mais estruturas rígidas. Estas são apenas manifestações estáveis de processos flexíveis que lhes estão subjacentes;

5) O pensamento em processo: Tal compreensão deu origem a um outro critério que explica o pensamento em termos de processo, significando que não só todas as coisas estão se transformando, mas tudo é fluxo e está em processo. Nada é definitivo. Da mesma maneira, não pode haver uma forma definitiva de determinado pensamento. Este tem que ser visto como estando em processo, com 
forma e conteúdo em perpétua mudança. O ponto principal é compreender que o processo não tem nenhum aspecto definível absolutamente fixo;

6) O conhecimento em rede: Da concepção do mundo como um fluxo universal de eventos $e$ processos decorre a mudança da metáfora do conhecimento como blocos fixos e imutáveis para o conhecimento em rede. Segundo esta teoria, o universo material é visto como uma teia dinâmica de eventos inter-relacionados e nenhuma das propriedades de qualquer parte da teia é fundamental. Todas resultam das propriedades das outras partes e a consistência global de suas interrelações determina a estrutura de toda a teia;

7) A unidade do conhecimento: No velho paradigma acreditava-se que as descrições científicas eram objetivas, isto é, eram independentes do observador humano e do processo de conhecimento. Porém, na mecânica quântica, o ato de observação altera a natureza do objeto. $O$ conhecimento do objeto depende do que ocorre dentro do sujeito, de seus processos internos, o que nos leva a crer que cada indivíduo organiza sua própria experiência;

8) Teorias transitórias: No velho paradigma o conhecimento poderia alcançar certeza absoluta e final. Hoje, torna-se importante reconhecer que a Ciência está sempre num processo de revisão. Não há verdades absolutas, permanentes, no sentido de uma identidade entre a descrição e a coisa descrita;

9) Auto-organização recursiva: $O$ conceito de auto-organização de Prigogine é um conceitochave, importante para a compreensão dos fenômenos da natureza. Ele possui um caráter aberto que induz ao entendimento de que o processo de desenvolvimento é uma sucessão ecológica em que uma etapa prepara a seguinte. A compreensão de que a criação do próximo estágio depende da contribuição parcial do anterior aproxima-se muito das ideias de Piaget, Brunner e Dewey;

10) Integração do qualitativo ao quantificável: O método empírico-quantitativo, baseado no paradigma positivista, busca os fatos ou as causas, prestando pouca atenção nos estudos subjetivos. É objetivo, excluindo os valores, orientado à comprovação. É reducionista, inferencial, hipotético e dedutivo. Almeja resultados que possam ser generalizados, mediante a comprovação dos dados, e utilizam metodologia estatística. É fragmentado, aleatório e não leva em consideração o contexto. Em resumo, é um método que implica um certo vazio teórico atrás de dados metodologicamente exatos. Segundo Lozano apud Moraes (2002), a corrente filosófica qualitativa está baseada no paradigma de investigação interpretativo ou hermenêutico. Busca a compreensão da natureza humana, mediante observação naturalista e sem controle estrito. É subjetivo, com valores explícitos, fundamentado no real, orientado ao processo. Quando possível, aceita a quantificação. É holista, histórico e considera o contexto.

E no tocante à educação, quais as implicações desse novo paradigma, que começou a redesenhar-se a partir do começo do século passado? Segundo Moraes (2002, p.83-106), na política educacional, no planejamento e nas propostas pedagógicas devese reconhecer a interconectividade dos problemas que não podem ser compreendidos isoladamente. Ela exige uma visão sistêmica e holística da realidade, como os processos vivos, e nos impõe a tarefa de integrar, articular, dar continuidade, tanto na parte teórica quanto na prática da educação. Com relação ao sujeito, na física quântica há a explicação de que o conhecimento decorre de uma relação indissociável entre o sujeito e o objeto. O conhecimento é produto de um sistema complexo, em que não é possível excluir ou controlar as variáveis, ou mesmo formas de explicação experimental. $\mathrm{O}$ indivíduo participa da construção do conhecimento, não apenas com o uso predominante do raciocínio e da percepção do mundo exterior pelos sentidos, mas também usando as sensações, os sentimentos, as emoções e a intuição para aprender, ou seja, utiliza-se da res extensa, do corpo e de seus sinais. O conhecimento não é um conjunto de verdades fixas, imutáveis, mas sim partes de uma forma abstraída 
de um processo de vir-a-ser, como afirmavam os filósofos pré-socráticos, principalmente Heráclito, que faz com que não haja elemento do conhecimento que seja absolutamente invariante. O conhecimento deve estar em rede. Todos os conceitos e todas as teorias estão interconectados. Não há conceitos em hierarquia. A visão do conhecimento em rede constitui um instrumento para a transformação potencial do próprio conhecimento. Reconhece-o como processo, algo que não possui um aspecto definível e absolutamente fixo.

A educação passa a ser compreendida como um sistema aberto, o que implica a existência de processos transformadores que decorrem da experiência, algo inerente a cada sujeito e que depende da ação, da interação e da transação entre sujeito e objeto, indivíduo e meio, da interação entre os educandos, e dos educandos com os professores, que agora também assumem a arte de serem orientares, facilitadores do conhecimento. Um sistema aberto significa que tudo está em movimento, é algo que não tem fim, em que o início e fim não são predeterminados, não são invariáveis. Cada final significa um novo começo, um recomeço, e cada início pressupõe a existência de um final anterior, o que faz com que o crescimento ocorra em espiral. Um sistema aberto exige um movimento contínuo e a cada ação completa é insumo para um novo começo.

A verdade científica, como por muito tempo foi encarada pelos profissionais da Ciência, passaria a ser concebida como teorias transitórias. Estas teorias representariam as introvisões ou formas de insights, que significam a maneira de observar o mundo em determinado momento. E como ocorrem sempre novos insights, estamos sempre gerando novas teorias, cada vez mais aproximadas da poesia queé a realidade.

O professor não é mais o dono de um conhecimento inquestionável, ele é a ponte, o facilitador de um conhecimento transitório, para algo além que seja mais próximo desta realidade mutante e viva. O princípio da complementaridade desenvolvido por Niels Bohr trouxe de volta o conceito de potencialidades e tendências ao reconhecer que todos os seres vivos são constituídos pela dualidade onda-partícula. Na medida em que um elétron pode ser partícula e onda, estar nesta ou naquela posição, tudo pode acontecer. Se observarmos a natureza e a evolução das coisas, podemos perceber que, às vezes, ela dá saltos gigantescos, imprevisíveis e não lineares de evolução e criatividade, e isso também deve ser proporcionado no espaço escolar, inclusive como critério de avaliação do rendimento escolar. Portanto, as avaliações não devem ser apenas pontuais, mas também formativas.

\section{CONSIDERAÇões Finais}

Enfim, baseado nestas três teorias - Teoria da Relatividade; Teoria Quântica e das Estruturas Dissipativas -, temos uma Nova Ciência que traz repercussões para todo o processo educativo. Com base nela, a educação deverá olhar para o educando como uma totalidade, um universo dentro do nosso universo, nas palavras de Da Vinci, como um ser indiviso, que construa seu conhecimento como outro (homem e natureza), usando a razão e a intuição, as sensações e as emoções, resultado de uma visão holística e sistêmica de realidade, da interação que há entre os seres vivos, os elementos da paisagem e os fenômenos da natureza. Esta compreensão do ser em sua totalidade e a reintegração do ser humano na sociedade e na natureza têm importantes implicações para a educação que queremos. Ganham espaço, então, as teorias educacionais de Ausubel, Brunner, Piaget, Vigotsky, entre outros.

\section{REFERÊNCIAS}

CAPRA, F. O ponto de mutação: a Ciência, a sociedade e a cultura emergente. $20{ }^{\mathrm{a}}-25{ }^{\mathrm{a}} \mathrm{Ed}$. São Paulo: Cultrix, 1999.

CAPRA, F. O Tao da física: um paralelo entre a física moderna e o misticismo oriental. 21. ${ }^{\mathrm{a}}-27 .{ }^{\mathrm{a}} \mathrm{Ed}$. São Paulo: Cultrix, 2001.

CAPRA, F. A teia da vida. $11 .^{\mathrm{a}}-18{ }^{\mathrm{a}} \mathrm{Ed}$. São

Paulo: Cultrix, 2007. 
COMTE, A. Discurso sobre o espírito positivo.

2. ${ }^{a}$ Ed. São Paulo: Editora da Universidade de São

Paulo, 1976.

DESCARTES, R. Discurso do método. 1. ${ }^{\text {a }}$ Ed.

São Paulo: Martin Claret, 2000.

ENGELS, F. A origem da família, da propriedade privada e do estado. $15 .{ }^{a}$ Ed. Rio de Janeiro:

Bertrand Brasil, 1995.

GUATTARI, F. As três ecologias. 11. ${ }^{\mathrm{a}}$ Ed. Papirus:

Campinas, 2001.

MORAES, M.C. O paradigma educacional

emergente. 8. ${ }^{\mathrm{a}}$ Ed. Campinas: Papirus, 2002.

OLIVEIRA, M. B. Oficina de jogos filosóficos -

pensar brincando. Disponível em: http://vsites.unb.br/ fe/tef/filoesco/resafe/numero002/textos/ oficina_marinesboliveira.htmAcesso em: [19/10/ 2010].

RUSSO, M; CARVALHO, C. A política educacional do governo Serra. Disponível em: www.simposioestadopoliticas.ufu/imagens/anais/pdf/ DC38.pdf Acesso em: [17/08/2010].

RUSSEL, B. História do pensamento ocidental. 3. ${ }^{\text {a }}$ Ed. Rio de Janeiro: Ediouro, 2001.

SANTOS, B.S. Um discurso sobre as Ciências.

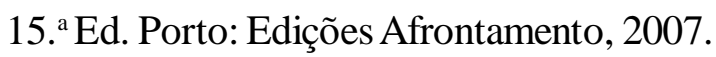

STIGAR, R. Os paradigmas da Ciência.

Disponível em: http://www.webartigos.com/articles/ 5776/1/Os-Paradigmas-Da-Ciencia/pagina1.html Acesso em: [10/11/2010].

RECEBIDO EM 24/11/2010

ACEITO EM 16/12/2010 